\title{
Reallocating the Right to Choose the Delivery Grade in Futures Markets
}

\author{
Shantaram Hegde ${ }^{1}$, Sankarshan Basu' ${ }^{2}$, Sunil K. Parameswaran ${ }^{3}$ \\ ${ }^{1}$ University of Connecticut, Storrs, USA \\ ${ }^{2}$ Indian Institute of Management Bangalore, Bangalore, India \\ ${ }^{3}$ Tarheel Consultancy Services, Bangalore, India \\ Email: shantaram.hegde@uconn.edu,sankarshanb@iimb.ernet.in, tarheelconsulting@gmail.com
}

How to cite this paper: Hegde, S., Basu, S. and Parameswaran, S.K. (2019) Reallocating the Right to Choose the Delivery Grade in Futures Markets. Theoretical Economics Letters, 9, 737-751.

https://doi.org/10.4236/tel.2019.94048

Received: January 30, 2019

Accepted: March 26, 2019

Published: March 29, 2019

Copyright $\odot 2019$ by author(s) and Scientific Research Publishing Inc. This work is licensed under the Creative Commons Attribution International License (CC BY 4.0).

http://creativecommons.org/licenses/by/4.0/

\begin{abstract}
We study the futures valuation and market manipulation implications of reallocating the right to choose the delivery grade from the short to the long futures position and show that the futures price will converge to the price of the most expensive-to-deliver grade asset at delivery. The shifting of the delivery grade option to the long has the potential to mitigate excessive selling of futures contracts in a crisis, thus contributing to price stabilization. However, it may distort the incentives for the longs, leading to large futures and "corner and squeeze" trades to raise the delivery time spot price above the locked-in futures price.
\end{abstract}

\section{Keywords}

Futures Valuation, Market Manipulation

\section{Introduction}

Futures prices should accurately reflect the price of the underlying asset. The concept of arbitrage is critical for understanding as to how spot prices and futures prices are linked. If the postulated relationship between the two prices is not satisfied, arbitrageurs will exploit the resulting profit opportunities until they are eliminated (Parameswaran [2011] [1]).

Traditionally, the right to choose the grade is given to the short position, in the case of futures contracts which permit more than one grade to be delivered. A consequence is that the futures price will converge to the delivery-adjusted spot price of the cheapest to deliver grade, which is a term used to refer to the grade with the lowest delivery-adjusted spot price (Garbade \& Silber, [1983] [2]; Kane \& Marcus, [1988] [3]; Kamara \& Siegel, [1987] [4]; Kamara, [1990] [5]; 
Hegde, [1989, 1990] [6] [7]; Chance \& Hemler, [1993] [8]; Hranajova \& Tomek, [2002] [9]; Wong, [2014] [10]). This paper examines a situation where the right to choose the grade is given to the long. It demonstrates that in such a situation, the long will choose to take delivery of the grade with the highest delivery adjusted spot price, or what may be termed as the most expensive to deliver grade.

Futures contracts provide a mechanism to lock in at time $t$ the purchase or sale price of an underlying asset on a future date $T(T>t)$. While this mechanism to buy insurance against price uncertainty protects the buyer (seller) from any increase (decrease) in price over time $t$ to $T$, it may also distort the incentives of traders to engage in potentially illegal price manipulations that they would not without the price protection. This situation is analogous to the moral hazard problem created by collision insurance contracts which increase the propensity of car drivers to operate vehicles recklessly (Cooper \& Ross, [1985] [11]; Boyer \& Dionne, [1989] [12]), and incentive call options that encourage executives to pursue risky investment policies (Core, Guay, \& Larcker, [2003] [13]).

Often price manipulations involve "corners and squeezes" (Jarrow, [1992] [14]; Cooper \& Donaldson, [1998] [15]; Pirrong, [2008] [16]). To mitigate this risk, most futures contracts assign the right to choose the grade (quality) of the deliverable underlying asset to the short futures trader, resulting in the convergence of futures price to the price of the cheapest-to-deliver grade at delivery $(\mathrm{T})$, as noted above. However, the allocation of delivery grade rights to the short does not address the potential problem of exacerbating a large short trader's incentives to sell futures, especially when the market is in distress, which can deepen a market crisis. The reallocation of the delivery grade option to the long position has the potential to mitigate the moral hazard problem by dampening the selling pressure in a crisis and contribute to price stabilization. However, the reallocation may distort the long trader's incentives to amass a large (long) futures position and engage in "corner and squeeze" trades in the underlying spot asset to raise the delivery time spot price above the current (locked-in) futures price.

The next section provides a brief survey of the related literature. Section 3 provides a detailed analysis of the current situation, where the right to choose the delivery grade is given to the short. Section 4 discusses the proposed change, that is, giving the right to choose the delivery grade to the long, and its implications for futures pricing and arbitrage. Section 5 examines the implications of reallocating the choice of grades to the long, and provides concluding remarks ${ }^{1}$.

\section{Literature Review}

There is a large literature on the right to choose the grade of the asset, timing,

${ }^{1}$ We are indebted to Stephen Figlewski for his incisive and insightful comments on an earlier version of this paper. 
and location of delivery often granted to the short position in futures contracts. Garbade \& Silber [1983] [2] examine the structure of premiums and discounts allowed on different grades of a commodity underlying future contracts and the effects of these quality adjustments on hedging. Kane \& Marcus [1988] [3] and Chance \& Hemler [1993] [8] show that the delivery options benefit the short position and the pre-delivery arbitrage-free futures price must be bid down by the value of the delivery options to compensate the long position for the added delivery risk. Hegde [1989, 1990] [6] [7] discusses ex-ante and ex-post empirical estimates of the value of the quality delivery option implicit in the Treasury bond futures contract. Analyzing the delivery basis risk embedded in a sample of soybean futures contracts, Kamara [1990] [5] observes that the futures price efficiently reflects the time-varying expected delivery basis and time-varying expected delivery risk premiums. While the delivery options may expand the deliverable supply and lower the risk of market manipulations (i.e., "corners and squeezes"), they tend to weaken the co-movement of the futures and the underlying spot prices and increase basis risk (Hranaiova \& Tomek, [2002] [9]). Wong [2014] [10] shows that the delivery risk associated with multiple delivery grades lowers a firm's production and affects its hedging position.

Jarrow [1992] [14] investigates conditions under which large traders (with market power) can manipulate markets, leading to price destabilizing speculation. Donaldson \& Cooper [1997] [15] show that when a large trader amasses a cornering interest in the underlying asset, price movements around contract expiration may not be driven by supply and demand fundamentals and may generate occasional price bubbles. Pirrong [2008] [16] indicates that corners and squeezes may distort production, consumption, and transportation of commodities, inject noise into price relations between spot and futures, weaken price informativeness and reduce the hedging effectiveness of derivatives contracts. Wong \& Zhao [2017] [17] study the real consequences of "short and distort" strategies of activist short-sellers (defined as those who publicly allege that stocks are overvalued so that the resulting price decline would benefit their short) positions. They report that the investment, financing, and payout activities of targeted firms drop in response to activist short-selling, along with improvement in their real efficiency.

The concepts of the delivery adjusted spot price and the cheapest to deliver grade, have been expounded in detail by Siegel \& Siegel [1990] [18]. Parameswaran [2011] [1] also studies this issue in detail.

\section{Futures Price: When the Right to Choose the Delivery Grade Is Allocated to the Short Position}

We will begin with the futures pricing implications of giving the right to choose the deliverable grade to the short, as is the current practice. As shown by prior studies, it has implications for the no-arbitrage futures price, both before and at expiration, and for arbitrage strategies. The price adjustment, when multiple grades are allowed, may be additive or multiplicative, and the relevant argu- 
ments are presented for both cases.

\subsection{Notation}

We will use the following symbols to denote the corresponding variables:

- $t \equiv$ the point in time at which we are standing, that is, today.

- $T \equiv$ the point in time at which the futures contract expires.

- $S_{t} \equiv$ current spot price of the asset underlying the futures contract.

- $F_{t} \equiv$ futures price of a contract initiated at time $t$ and expiring at time $T$.

- $r \equiv$ rate of interest for the period between $t$ and $T$ (not annualized).

- $a_{i} \equiv$ price adjustment factor for grade $i$.

- $I \equiv$ the future value of any payouts from a financial asset during the life of the contract, as computed at its point of expiration.

- $Z \equiv$ the future value of any storage costs incurred during the life of the contract in the case of physical assets, as computed at the time of contract expiration.

- $Y \equiv$ marginal convenience value.

\subsection{Spot-Futures Price Relationship without the Delivery Grade Option}

The use of the no-arbitrage, and no-quasi arbitrage arguments to price futures contracts is standard, and can be found in books by authors such as Hull [2014] [19], Kolb \& Overdahl [2007] [20], McDonald [2013] [21], and Siegel \& Siegel [1990] [18]. To rule out arbitrage in the absence of the right to choose the delivery grade, we require that

$$
F_{t}=S_{t}(1+r)-I
$$

for financial assets, and

$$
F_{t}=S_{t}(1+r)+Z
$$

for physical commodities.

If the market is not at full carry, the corresponding relationship for a physical asset would be

$$
F_{t}=S_{t}(1+r)+Z-Y
$$

where $Y$ is the marginal convenience value.

If the futures contract were to be overpriced, an arbitrageur would engage in cash and carry arbitrage. The rate of return from such a strategy is termed as the Implied Repo Rate (IRR), and a cash and carry strategy is profitable if the IRR is greater than the borrowing rate. If the futures contract were to be under-priced, the traders would resort to reverse cash and carry arbitrage. The cost of such a strategy is termed as the Implied Reverse Repo Rate (IRRR), and it is profitable only if the IRRR is less than the lending rate. Assuming that the borrowing and lending rates are equal, the lack of arbitrage opportunities would imply the pricing relationships given above. At the point of expiration, we get the spotfutures convergence relationship, that is $F_{T}=S_{T}$. Thus in the case of futures 
contracts where a single grade is allowed for delivery, the spot and futures prices should converge at expiration.

\subsection{Multiple Deliverable Grades}

In practice, the short is often given a choice of grades, time and location of delivery. We focus on the choice of grades and ignore the choices given to the shorts, with respect to time and location of delivery. An important issue is, which spot price will the futures price converge to, since each grade will have its own spot price. Siegel \& Siegel [1990] [18] invoke the no-arbitrage argument to demonstrate the properties of the futures price. They define the cheapest to deliver (CTD) grade, in the case of additive as well as multiplicative adjustment mechanisms, and demonstrate the spot-futures relationship, both prior to maturity, and at maturity. Accounting for multiple delivery grades entails two price adjustments. The first is the premium or discount for the deliverable grade chosen by the short. The second price adjustment concerns the value of the short's right (i.e., the delivery grade option) to choose the CTD grade. We will first analyze the cost of carry model and its consequences for the relationship between spot and futures prices, both at the time of delivery $T$ as well as prior to $T$ while ignoring the delivery grade option. We will subsequently incorporate a delivery grade option premium.

Certain futures contracts give the short the flexibility to deliver more than one grade of the underlying asset. The exchange will in such cases, designate one grade as the Par grade. If the short were to deliver the par grade, he will receive the prevailing futures price at expiration, $F_{T}$, at the time of delivery. However, if he were to deliver a more valuable grade, he will receive a premium, whereas if he were to deliver a less valuable grade, he would have to do so at a discount. There are two ways of incorporating the premium or discount for grades other than the par grade, known as multiplicative adjustment and additive adjustment.

\subsubsection{Additive Adjustment for the Deliverable Grade at $T$}

Let us consider the case of contracts, which permit more than one grade to be delivered, and use an additive system of price adjustment. In the case of such contracts, the short will receive $F_{T}+a_{i}$, if he were to deliver grade $i$, where $a_{i}$ is the adjustment factor for the grade in question. One grade will be designated as the par grade, and will have an adjustment factor of zero. For a premium grade, $a_{i}$ will be positive, whereas for a discount grade, it will be negative. Such a price adjustment system is used for contracts on agricultural commodities.

We will denote the spot price of grade $i$ at expiration by $S_{i, T}$. Hence, the profit for the short if he were to deliver grade $i$ is:

$$
F_{T}+a_{i}-S_{i, T}
$$

The grade chosen for delivery will be the one for which $S-a$ is the lowest. That is, grade $i$ will be the preferred grade if

$$
S_{i, T}-a_{i}<S_{j, T}-a_{j} \forall j
$$


To rule out arbitrage, the profit from delivering the most desirable grade must be zero. That is

$$
F_{T}=S_{i, T}-a_{i}
$$

$S-a$ is termed as the Delivery Adjusted Spot Price, and the grade with the lowest delivery adjusted spot price is termed as the cheapest to deliver grade (CTD). Thus the futures price will converge to the delivery adjusted spot price of the cheapest to deliver grade.

\subsubsection{Multiplicative Adjustment for the Deliverable Grade at $T$}

In the case of contracts which permit more than one grade of the underlying asset to be delivered, and which specify a multiplicative system of price adjustment, the short will receive an amount equal to $a_{i} F_{T}$ at the time of delivery, if he were to deliver grade i. For premium grades, $a_{i}$ will be greater than 1.0, whereas for discount grades, it will be less than 1.0. The par grade will have an adjustment factor of one. Such a price adjustment system is used for gold futures and T-Bond futures. We continue to ignore the delivery grade option-induced price adjustment in this discussion.

The profit for an arbitrageur were grade $i$ to be delivered is:

$$
a_{i} F_{T}-S_{i, T}
$$

At expiration, in order to preclude arbitrage, the profit from delivering the most preferred grade must be zero. If we denote this grade as grade $i$, it must be the case that

$$
\begin{aligned}
& a_{i} F_{T}-S_{i, T}=0 \\
& \Rightarrow F_{T}=\frac{S_{i, T}}{a_{i}}
\end{aligned}
$$

Thus, the grade that will be chosen for delivery will obviously be the one for which $\frac{S}{a}$ is the lowest. Such a grade is called the Cheapest to Deliver Grade $(C T D)$ and $\frac{S}{a}$ is called the Delivery Adjusted Spot Price.

At expiration, therefore, the futures price must converge to the delivery adjusted spot price of the cheapest to deliver grade, irrespective of whether an additive or a multiplicative system of price adjustment is in use. The only difference lies in the definition of the delivery adjusted spot price.

\subsection{No-arbitrage Futures Price Prior to Expiration (at $t$ )}

In the case of multiple deliverable grades, cash and carry arbitrage can be initiated with any of the allowable grades. Thus each grade will have its own Implied Repo Rate. Arbitrage activities will continue till there is no profit to be made from any of the deliverable grades. The cheapest to deliver grade prior to expiration will be the one that maximizes the IRR, which, in an arbitrage free setting will just equal the borrowing rate. If we call this grade $i$ then (ignoring for the moment the delivery option value) 


$$
\begin{aligned}
& \frac{F_{t}+a_{i}-S_{i, t}}{S_{i, t}}=r \\
& \Rightarrow F_{t}=S_{i, t}(1+r)-a_{i}
\end{aligned}
$$

We will define $S_{i, t}(1+r)$ as the no-arbitrage futures price. Thus the futures price prior to expiration will be equal to the delivery-adjusted no-arbitrage futures price of the cheapest to deliver grade.

In the case of a multiplicative system of adjustment, the equivalent condition would be

$$
\begin{gathered}
\frac{a_{i} F_{t}-S_{i, t}}{S_{i, t}}=r \\
F_{t}=\frac{S_{i, t}(1+r)}{a_{i}}
\end{gathered}
$$

\subsection{Incorporating the Delivery Option Premium at $t$}

When the choice of grade is given to the short, the short has the right to choose the CTD grade for delivery at $T$. As the short is implicitly buying the right to sell (i.e., deliver) the CTD grade, he is effectively going long on a put option on the underlying asset. The long futures trader has sold this embedded put option to the short. The premium compensates the long for the (delivery) risk that the short may deliver a different grade at the time of expiration than the CTD grade prior to delivery. Following Kane \& Marcus [1988] [3], Hegde [1989, 1990] [6] [7], and Chance \& Hemler [1993] [8], the no-arbitrage condition may be expressed as:

$$
F_{t}=S_{i, t}(1+r)-a_{i}-P_{t}
$$

or as

$$
F_{t}=\frac{S_{i, t}}{a_{i}}(1+r)-P_{t}
$$

At delivery $\mathrm{T}$, the (implied) payoff to the embedded delivery grade put option held by the short is equal to the maximum of the following two values (assuming additive adjustment for grade differences):

1) zero, when the CTD grade at $t$ continues to be CTD at $T$ (i.e., the delivery option expires out-of-the money), and

2) $\left[\left(S_{i, T}-a_{i}\right)-\left(S_{j, T}-a_{j}\right)\right]$, where $i$ refers to the CTD grade at $t$ and $j$ denotes the CTD grade at $T$. In other words, the delivery grade put option allows the short to switch from grade $i$ to grade $j$ at the time of delivery, thus lowering his cost of delivering the underlying asset. Note that since the put is embedded in the futures contract, that is, it is not an explicit (stand-alone) option, the delivery time payoff is implicit in the futures price. So in the case of an additive adjustment for difference in deliverable grades the embedded put option payoff is:

$$
\max \left[0,\left(S_{i, T}-a_{i}\right)-\left(S_{j, T}-a_{j}\right)\right]
$$


The equivalent expression for the case of a multiplicative adjustment:

$$
\max \left[0, \frac{S_{i, T}}{a_{i}}-\frac{S_{j, T}}{a_{j}}\right]
$$

\section{Futures Price: Reallocating The Delivery Grade Choice to the Long}

What would happen if the long in the case of a futures contract is given the right to initiate delivery and choose one among several deliverable grades? We will consider first the case of additive adjustment, and then extend the logic to contracts which specify multiplicative adjustment (while suppressing the price adjustment due to the delivery grade option).

\subsection{The Cost of Carry Model with Additive Price Adjustment and No Delivery Grade Option Premium}

If the long were to demand delivery of grade $i$, he would have to pay $F_{T}+a_{i}$. The item can then be sold at the prevailing spot price of $S_{i, T}$. The profit from the transaction $=S_{i, T}-\left(F_{T}+a_{i}\right)$. Grade $i$ will be preferred to grade $j$ if

$$
\begin{aligned}
& S_{i, T}-\left(F_{T}+a_{i}\right)>S_{j, T}-\left(F_{T}+a_{j}\right) \\
& \Rightarrow S_{i, T}-a_{i}>S_{j, T}-a_{j}
\end{aligned}
$$

To rule out arbitrage the most preferred grade must give a profit of zero. Thus

$$
\begin{aligned}
& S_{i, T}-\left(F_{T}+a_{i}\right)=0 \\
& \Rightarrow F_{T}=S_{i, T}-a_{i}
\end{aligned}
$$

For all other grades

$$
\begin{aligned}
& S_{j, T}-\left(F_{T}+a_{j}\right)<0 \\
& \Rightarrow F_{T}>S_{j, T}-a_{j} \forall j
\end{aligned}
$$

Thus the futures price will be equal to the delivery adjusted spot price of the grade with the highest delivery adjusted spot price, or what may be termed as the most expensive to deliver grade.

\subsection{Multiplicative Adjustment}

In the case of contracts which permit more than one grade of the underlying asset to be delivered, and which specify a multiplicative system of price adjustment, the long will pay an amount equal to $a_{i} F_{T}$ at the time of delivery, if he were to accept delivery of grade $i$. He can then sell the asset at the prevailing spot price of $S_{i, T}$.

Hence, the profit for the long if he were to demand delivery of grade $i$ is:

$$
S_{i, T}-a_{i} F_{T}
$$

Grade $i$ will be preferred to another grade $j$ if

$$
S_{i, T}-a_{i} F_{T}>S_{j, T}-a_{j} F_{T}
$$

At expiration, in order to preclude arbitrage, the profit from receiving delivery 
of the most preferred grade must be zero. If we denote this grade as grade $i$, it must be the case that

$$
\begin{aligned}
& S_{i, T}-a_{i} F_{T}=0 \\
& \Rightarrow F_{T}=\frac{S_{i, T}}{a_{i}}
\end{aligned}
$$

In the case of all other grades, it must be the case that

$$
\begin{aligned}
& S_{j, T}-a_{j} F_{T}<0 \\
& \Rightarrow F_{T}>\frac{S_{j, T}}{a_{j}}
\end{aligned}
$$

Thus, the grade that will be chosen for delivery will obviously be the one for which $\frac{S}{a}$ is the highest. Thus while the definition of the delivery adjusted spot price would remain the same, namely $\frac{S}{a}$, the preferred grade for delivery, will be the one with the highest delivery adjusted spot price.

At expiration, therefore, the futures price must converge to the delivery adjusted spot price of the most expensive to deliver grade, irrespective of whether an additive or a multiplicative price adjustment system is in use.

\subsection{Futures Price Prior to Expiration without the Delivery Grade Option Premium}

The longs will implement reverse cash and carry arbitrage strategies till the profit from the most desirable grade is zero. The preferred grade will be the one for which

$$
\begin{aligned}
& \frac{a_{i} F_{t}-S_{i, t}}{S_{i, t}}=r \\
& \Rightarrow F_{t}=\frac{S_{i, t} \times(1+r)}{a_{i}}
\end{aligned}
$$

For all other grades

$$
\begin{aligned}
& \frac{a_{j} F_{t}-S_{j, t}}{S_{j, t}}>r \\
& \Rightarrow F_{t}>\frac{S_{j, t} \times(1+r)}{a_{j}}
\end{aligned}
$$

In other words the futures price prior to expiration will be equal to the no-arbitrage price of the most expensive to deliver grade.

The equivalent condition for additive adjustment would be:

$$
F_{t}=S_{i, t}(1+r)-a_{i}
$$

For all other grades, $F_{t}>S_{j, t}(1+r)-a_{j}$.

\subsection{Incorporating the Delivery Grade Option Premium}

In such situations the long futures trader owns an embedded call option (sold by 
the short) to demand delivery of the most expensive grade as of time $T$. She purchases this flexibility by buying the implicit delivery grade call option. Because of this delivery option the futures price, $F_{t}^{\prime}$, will be higher than what the standard cost of carry model would predict, $F_{t}$. The difference, $\left(F_{t}^{\prime}-F_{t}\right)$ is equal to the delivery grade call option premium, $C_{t}$. In other words the short is exposed to the risk that he may have to deliver the most expensive grade. To compensate him for this delivery risk, the short receives the call premium embedded in the (higher) futures price, $F_{t}$. The pricing relationship in the presence of the implied call option is:

$$
\Rightarrow F_{t}^{\prime}=\frac{S_{i, t} \times(1+r)}{a_{i}}+C_{t}
$$

or

$$
F_{t}^{\prime}=S_{i, t}(1+r)-a_{i}+C_{t}
$$

\subsection{Payoffs From the Delivery Grade Call Option}

If the grade (i) chosen at the outset were to remain the costliest to deliver at the time of delivery (T), the call option will expire out of the money and the payoff will be zero. However if another grade ( $j$ ) were to become the costliest to deliver at $T$ then the payoff under additive adjustment for quality is

$$
\max \left[0,\left(S_{j, T}-a_{j}\right)-\left(S_{i, T}-a_{i}\right)\right]
$$

The equivalent condition for multiplicative adjustment is

$$
\max \left[0,\left(\frac{S_{j, T}}{a_{j}}-\frac{S_{i, T}}{a_{i}}\right)\right]
$$

\section{The Rationale for Allotting the Delivery Option to the Shorts}

Allowing multiple delivery grades expands the supply of the deliverable product and reduces the risk of corners and squeezes for a contract, so long as it is the party making delivery that gets to choose. If the cheapest to deliver grade becomes scarce, its price will rise until the previously second cheapest to deliver grade also begins to be delivered, which expands the supply. However, if we were to allow the longs to choose the deliverable grade, the consequences would be the opposite. It would let the longs pick the grade with the narrowest supply and the most difficult conditions for delivery and insist on receiving that grade. The price of the "most expensive to deliver" grade would be driven up in absolute terms and relative to that of other less expensive grades. Short hedgers who want to make delivery would have to liquidate their spot positions in whatever grade of the commodity they had been trying to hedge and acquire the specific grade that their counterparty demands. The price distortion would produce tremendous basis risk for most hedgers, whether they choose to close out their futures positions by delivery or by offsetting. Thus from this perspective, there does not 
appear to be a valid rationale for reallocating the option to choose the deliverable grade. However as we mention in the following section, there could be a situation where allocating the right to choose the deliverable grade to the longs may have some merit. When a market is in distress, as characterized by rapidly declining prices, regulators and exchanges often suspend trading as a response, or else impose price limits or modify the required margins. In such situations an alternative may be to temporarily reassign the delivery option to the longs, albeit as a short-term measure.

\section{Concluding Remarks}

Traditionally, many futures contracts permit more than one grade of the underlying asset to be delivered and assign the right to choose the grade to the short. For instance futures contracts based on agricultural products such as wheat, give a choice of grades, and prescribe an additive method of price adjustment. Futures contracts on gold and Treasury bonds, also give an option to the shorts, but prescribe a multiplicative method of price adjustment. This practice makes the futures price converge to the delivery-adjusted spot price of the cheapest-todeliver grade. We study the futures valuation and market manipulation implications of reallocating the right to choose the delivery grade from the short to the long futures position. Our analysis shows that with such reallocation the futures price converges to the price of the most expensive-to-deliver grade at delivery, as opposed to the current situation where it converges to the price of the cheapest to deliver grade. While this per se may not at first glance appear to be serious, closer analysis reveals that in practice this could lead to severe price distortion and basis risk. However, the alternative may not be entirely without merit. As discussed in the next section, the shifting of the delivery grade option to the long has the potential to relieve the excessive selling pressure in the spot and futures markets in a crisis, thus reducing systemic risk. However, the reallocation may distort the traders' incentives, leading to "corners and squeezes". Therefore, in the next section we discuss the caveat that the benefit of reallocating the delivery grade option to the long may be limited to its temporary use in stabilizing a market in crisis. This in essence is the main contribution of the paper.

The paper presents the theory behind the alternative to the current approach adopted by futures exchanges in the case of contracts that permit multiple grades to be delivered. However this could pose its own problems, as a consequence of which an alternative to the current practice may have a limited utility in a situation where a market is in severe distress. The empirical implications of this may be the focus of study of subsequent research.

\section{Implications for Market Manipulation and Basis Risk}

A trader who intends to buy an asset at a future date faces the risk that the price may rise (upward price risk). She can buy insurance against a rise in price by buying a futures contract (i.e., take a long position in futures). In contrast, a 
trader who intends to sell an asset at a future date faces the risk that the price may fall (downward price risk). He can buy protection against a fall in price by selling a futures contract (i.e., take a short position in futures). Thus, futures trading enables both the long and the short to buy insurance against price uncertainty in properly functioning derivatives markets. However, this price fixing mechanism for future purchase or sale may create a moral hazard problem, especially when an exogenous positive (negative) shock causes a sharp rise (drop) in prices.

Futures contracts are highly leveraged instruments in the sense that they are subject to much lower margin requirements (considering both initial and maintenance margins and daily marking to market) as compared to trading in underlying assets, such as, commodities, stocks and bonds). The literature on conflicts of interest between bond holders and stockholders in corporate finance indicates that excessive debt may distort the incentives of shareholders (with limited liability) to shift risk to debt holders by selecting high-risk investments (Jensen \& Meckling [1976] [22]). In a similar fashion, by providing a mechanism at time $t$ to fix the price for future (time $T>t$ ) purchase or sale, derivative contracts may encourage large short (long) traders to expand their positions in the spot and/or derivatives markets to gain market power and manipulate prices. Market manipulations include attempts to inflate as well as deflate prices beyond levels justified by supply and demand fundamentals. Such attempts are more likely in response to an exogenous shock (e.g., a drought or good weather conditions) that depresses (boosts) market prices.

As Jarrow [1992] [14], Cooper \& Donaldson [1998] [15], and Pirrong [2008] [16] indicate, the future price fixing mechanism can make a market susceptible to the exercise of market power by large long and short traders. Let us first consider the situation when there is no delivery grade option. After entering the futures trade at time $t$, the long and other non-derivatives traders have an incentive to corner the market and try to raise the delivery time $(T)$ price of the underlying asset, thus squeezing the short. This attempt to corner and squeeze could coincide with a natural adverse supply shock such as a drought in agricultural produce markets, or an unexpected reduction in the issue of the underlying T-bonds. To mitigate this corner risk, many futures contracts grant a delivery option to the short side of the market, allowing them to choose the cheapest-to-deliver (CTD) grade of the underlying asset for delivery.

In the absence of the delivery grade option, there is a price manipulation risk other than the corner risk. This is due to the short traders' incentive to depress the underlying asset price through short-selling the spot asset to push down the delivery time price of the underlying asset (Diamond, [1987] [23]). Let us call it "deflation risk" (short and distort). Since short-selling the spot asset, especially, commodities, is more complex and costly, deflation risk seems to be not as much a concern as corner risk. This attempt to depress the market could coincide with natural positive supply shocks such as a bountiful harvest (great weather conditions) in agricultural produce markets, or an unexpected increase in the 
issue of the underlying government bonds. This deflation risk may be exacerbated by the assignment of the right to select the delivery grade to the short because the delivery time spot futures price converges to the delivery adjusted spot price of the CTD grade, thus encouraging the short and non-derivatives traders to pursue strategies to depress market price. Moreover, it may further distort the correlation between the futures price and the underlying spot price, thus increasing basis risk (Kamara, [1990] [5]; Hranaiova \& Tomek, [2002] [9]). This type of short and distort incentive can be mitigated by assigning the delivery grade option to the long side of the market. As shown earlier, this reallocation of the delivery grade option would make the terminal futures price converge to the delivery adjusted spot price of the costliest-to-deliver grade, since the long will select the most expensive grade for delivery. Thus, the reallocation serves to curb the short trader's incentive to depress the underlying asset price.

Price manipulation incentives (moral hazard-induced trading activities) are typically mild in a stable and healthy market environment, but they become stronger when the underlying asset market faces a crisis involving sharp price declines. To illustrate the potential price stabilization benefits of the reallocation of delivery rights to the long, consider a market under stress, marked by a downward price spiral. In such a case, regulators and security exchanges tend to take the drastic action of suspending trading, imposing daily price limits and raising margin requirements (Brennan, [1986] [24]). But those interventions are prone to delaying price adjustment to changing market conditions in a crisis. A less drastic regulatory action that offers the benefit of keeping the market open is to reallocate the delivery grade rights to the long futures trader when the market is in distress. It would diminish the selling pressure, strengthen the demand for grades with higher delivery-adjusted spot prices, and help stabilize the market in turmoil.

A potential shortcoming with reallocating the delivery grade option is it may distort the long traders' incentives to accumulate a large (long) futures position, gain market power, and engage in "corner and squeeze" trades in the underlying spot asset to raise the delivery time spot price above the current (locked-in) futures price. Further, such manipulations are likely to increase price volatility, weaken the correlation between the futures price and the underlying spot price and lead to higher basis risk. This disadvantage suggests that main benefit of reallocating the delivery grade option to the long is limited to its temporary use in curbing excessive short-selling in a market crisis.

\section{Conflicts of Interest}

The authors declare no conflicts of interest regarding the publication of this paper.

\section{References}

[1] Parameswaran, S.K. (2011) Futures and Options: Concepts and Applications. McGrawHill, Singapore. 
[2] Garbade, K.D. and Silber, W.L. (1983) Futures Contracts on Commodities with Multiple Varieties: An Analysis of Premiums and Discounts. The Journal of Business, 56, 249-272.

[3] Kane, A. and Marcus, A.J. (1988) The Delivery Option on Forward Contracts: A note. Journal of Financial and Quantitative Analysis, 23, 337-341. https://doi.org/10.2307/2331072

[4] Kamara, A. and Siegel, A.F. (1987) Optimal Hedging in Futures Markets with Multiple Delivery Specifications. The Journal of Finance, 42, 1007-1021. https://doi.org/10.1111/j.1540-6261.1987.tb03924.x

[5] Kamara, A. (1990) Delivery Uncertainty and the Efficiency of Futures Markets. Journal of Financial and Quantitative Analysis, 25, 45-64. https://doi.org/10.2307/2330887

[6] Hegde, S.P. (1989) On the Value of the Implicit Delivery Options. The Journal of Futures Markets, 9, 421-437. https://doi.org/10.1002/fut.3990090505

[7] Hegde, S.P. (1990) An ex Post Valuation of the Quality Alternative Implicit in the Treasury Bond Futures Contract. The Journal of Banking and Finance, 14, 741-760.

[8] Chance, D.M. and Hemler, M.L. (1993) The Impact of Delivery Alternatives on Futures Prices: A Survey. The Journal of Futures Markets, 13, 127-155. https://doi.org/10.1002/fut.3990130203

[9] Hranaiova, J. and Tomek, W. (2002) Role of Delivery Options in Basis Convergence. The Journal of Futures Markets, 22, 783-809.

[10] Wong, K. (2014) Production and Hedging in Futures Markets with Multiple Delivery Specifications. Decisions in Economics and Finance, 37, 413-421. https://doi.org/10.1007/s10203-013-0152-Z

[11] Cooper, R. and Ross, T.W. (1985) Product Warranties and Double Moral Hazard. The RAND Journal of Economics, 16, 103-113. https://doi.org/10.2307/2555592

[12] Boyer, M. and Dionne, G. (1989) An Empirical Analysis of Moral Hazard and Experience Rating. The Review of Economics and Statistics, 71, 128-134. https://doi.org/10.2307/1928059

[13] Guay, W.R., Core, J.E. and Larcker, D.F. (2003) Executive Equity Compensation and Incentives: A Survey. FRBNY Economic Policy Review, 9, 27-50.

[14] Jarrow, R. (1992) Market Manipulation, Bubbles, Corners, and Short Squeezes. The Journal of Financial and Quantitative Analysis, 27, 311-336. https://doi.org/10.2307/2331322

[15] Cooper, D.J. and Donaldson, G.R. (1998) A Strategic Analysis of Corners and Squeezes. The Journal of Financial and Quantitative Analysis, 33, 117-137. https://doi.org/10.2307/2331380

[16] Pirrong, C. (2011) Squeeze Play: The Dynamics of the Manipulation End Game. The Journal of Alternative Investments, 14, 26-39.

[17] Wong, Y.T.F. and Zhao, W. (2017) Post-Apocalyptic: The Real Consequences of Activist Short-Selling. Marshall School of Business Working Paper No. 17-25.

[18] Siegel, D.R. and Siegel, D.F. (1990) Futures Markets. The Dryden Press, New York.

[19] Hull, J.C. (2014) Options, Futures and Other Derivatives. Prentice Hall, Upper Saddle River, NJ.

[20] Kolb, R.W. and Overdahl, J.A. (2007) Futures, Options, and Swaps. Wiley-Blackwell, Hoboken, NJ.

[21] McDonald, R.L. (2013) Derivatives Markets, Pearson, London. 
[22] Jensen, M.C. and Meckling, W.H. (1976) Theory of the Firm: Managerial Behavior, Agency Cost, and Capital Structure. Journal of Financial Economics, 3, 305-360.

[23] Diamond, D.W. (1987) Constraints on Short-Selling and Asset Price Adjustment to Private Information. Journal of Financial Economics, 18, 277-311. https://doi.org/10.1016/0304-405X(87)90042-0

[24] Brennan, M.J. (1986) A Theory of Price Limits in Futures Markets. Journal of Financial Economics, 16, 213-233. https://doi.org/10.1016/0304-405X(86)90061-9 